cost-effective tool. However, most JEMs are built from the assessment of jobs held by men, with few studies assessing the applicability of those JEMs to the same jobs when held by women.

Objective To compare within-occupation exposure assessments for jobs held by men versus women in a Canadian JEM (CANJEM).

Method Two sex-specific JEMs were created using data from CANJEM, a JEM based on the expert assessment of exposure to 258 chemicals in $>30,000$ jobs held during 1933-2005, by participants in five Montreal-based case-control studies. Each cell in the JEMs provided the probability, intensity, frequency, and frequency-weighted intensity (FWI) of exposure to a selected occupational agent, for a specific combination of a 4digit Canadian Classification and Dictionary of Occupations code and one of four time periods. We used intra-class correlation coefficients (ICC) to compare the probability, frequency and FWI between cells considered exposed in the two JEMs; 'exposed' cells were defined by probability $\geq 5 \%$. Given the semi-quantitative nature of intensity, Kendall's Tau $(\tau)$ was used. We further compared differences between the JEMs using empirical cumulative distribution functions (ECDF).

Results In total, 1,488 cells considered exposed in both JEMs were included in the analysis. ICC (95\% confidence interval) of $0.58(0.55-0.61), 0.55(0.52-0.58)$ and $0.12(0.07-0.17)$ were found for probability, frequency and FWI of exposure, respectively. For intensity, a $\tau$ of $0.24(0.20-0.29)$ was found. The ECDFs showed a tendency for frequency to be higher in the female-JEM, but for intensity and FWI to be higher in the male-JEM. No clear trend was observed for probability of exposure.

Conclusion Our results suggest that CANJEM assessment of jobs held by men was inadequate to estimate exposure in women's.

\section{P-338 PROBLEMS OF THE SANITARY AND EPIDEMIOLOGICAL SERVICE IN THE FIGHT AGAINST COVID-19}

'Baktiyar Kairzhan, Asset Izdenov, Nazgul Izdenova. 'West Kazakhstan Marat Ospanov Medical University, Kazakhstan

\subsection{6/OEM-2021-EPI.276}

Introduction The State Sanitary and Epidemiological Surveillance in the Republic of Kazakhstan is carried out by the Committee for Sanitary and Epidemiological Control, which is a unified centralized system for the prevention, detection, suppression of violations in the field of ensuring the sanitary and epidemiological well-being of the population in order to protect the health of the population and the human environment. The pandemic of a novel Coronavirus Disease 2019 (COVID19) caused by the severe acute respiratory syndrome SARSCoV2 has posed a severe global crisis. During the COVID-19 pandemic, this service took full control, monitoring and analysis of work to combat coronavirus infection. The purpose of infection control is to prevent and combat the emergence of acute infectious diseases among the population. The activities of the committee are aimed at: 1 . Protection of public health. 2. Sanitary and epidemiological welfare of the population. 3. Anti-corruption activities. 4. Control and supervision over compliance with the requirements established by technical regulations in the country.
Methods An analysis was made of the structure of this state body, its activities, the number of employees and the results of their work.

Results and Conclusion There was a high shortage of specialist epidemiologists in this industry during the pandemic. After analyzing the activities of the sanitary and epidemiological service, we came to the conclusion that these problems arose in connection with the constant reorganization of this service. Over the period of 10 years (2010-2020), there have been transformations and changes in the committee for sanitary and epidemiological control more than 6 times, which significantly influenced the work of the sanitary and epidemiological service and its weakening. It should be noted that over the years of its existence, the service has been one of the main ones in protecting the health of the population of Kazakhstan.

\section{P-339 THE IMPORTANCE OF TRAINING DOCTORS EPIDEMIOLOGISTS IN THE REPUBLIC OF KAZAKHSTAN}

${ }^{1}$ Baktiyar Kairzhan, Asset Izdenov, Nurbek Yerdessov. 'West Kazakhstan Marat Ospanov Medical University, Kazakhstan

\subsection{6/OEM-2021-EPI.277}

Introduction In the history of development, humanity has tried to avoid the spread of diseases. It is known from historical sources that humanity has suffered about 50 pandemics. The main specialist in solving problems of infection control is the 'Epidemiologist'; his task is to prevent diseases and take appropriate preventive measures to prevent and spread diseases.

Objectives The purpose of this work is to analyze the training of doctors of the sanitary and epidemiological profile.

Methods An analysis of the training system for specialists in the sanitary and epidemiological profile was carried out, taking into account the study of specialized subjects, as well as an analysis of the lack of specialists in this industry.

Results and Conclusion Earlier in the Republic of Kazakhstan, there were 5 medical universities in which doctors-epidemiologists-hygienists were trained for the sanitary-epidemiological service. At the moment, there are 7 medical universities, which train specialists in the new specialty 'Public health'. After analyzing the training system for specialists in the sanitary and epidemiological profile, we discovered in 2020 during the COVID-19 pandemic in the Ministry of Health of the Republic of Kazakhstan, there was a shortage of more than 800 epidemiologists and specialists of the sanitary and epidemiological service, which significantly influenced the fight against coronavirus infection. From this it can be concluded that medical universities need to: 1. Open new faculties to train doctors-epidemiologists-hygienists; 2 . to intensify the recruitment of new applicants for this specialty of a sanatorium-epidemiological profile; also, government agencies need to allocate additional grants for such applicants. The Sanitary and Epidemiological Service has played an important role in the history of the well-being of the population of the Republic of Kazakhstan. Over the years of its existence, the service has been one of the main ones in protecting the health of the population of Kazakhstan. 